\title{
A rare case of cytomegalovirus presentation in a hemodialysis patient
}

\author{
Liesbeth De Waele*1, Katrien Wierckx², Anne-Marie Bogaert ${ }^{3}$ \\ ${ }^{1}$ Antwerp University Hospital, Antwerp, Belgium \\ ${ }^{2}$ Ghent University Hospital, Ghent, Belgium \\ ${ }^{3}$ AZ St-Elisabeth, Zottegem, Belgium
}

Received: April 25, 2017

DOI: $10.5430 /$ crim.v4n $3 p 79$
Accepted: August 13, 2017

Online Published: August 30, 2017

\begin{abstract}
Background: Cytomegalovirus (CMV) infection is a common viral infection in humans with a diverse manifestation, mostly dependent on the host. CMV infection in the immunocompetent host is generally asymptomatic or may present as a mononucleosis syndrome. Infection in immunocompromised patients cause substantial morbidity and mortality.

Case representation: We report a rare manifestation of a CMV infection in a 87-year-old male with end-stage renal failure with dialysis dependency and diabetes who presents with diffuse abdominal pain and nausea. Further assessment with a CT scan of the abdomen showed a thickening of the wall of the preterminal ileum, suggestive of focal enteritis. Ileocolonoscopy showed a partial circular ulcerated mucosa of the preterminal ileum, biopsies showed ulcerations, etiology was unknown. A few days later he develops melena and anemia of $7.2 \mathrm{~g} / \mathrm{dl}$. Further exploration with gastroscopy was normal. A new colonoscopy showed no abnormalities; however the terminal ileum could not be visualized. An urgent laparotomy was performed because of hemodynamic instability and showed an ulcus of $7 \mathrm{~cm}$ with a thickened terminal ileum. An enterectomy of the inflammated part of the ileum was performed. Histopathology of the ulceration showed the presence of CMV inclusions in the vascular endothelium of the capillaires of the ileal segment. Serologic examination showed nonreactive CMV IgM antibodies and IgG antibodies were positive. PCR CMV showed 300 copies/ml (whole blood). Treatment with intravenous ganciclovir was started with good clinical and biochemical response.

Conclusions: In the differential diagnosis CMV disease should be considered in any ulceration in the gastro-intestinal tract in the immunocompromised patient.
\end{abstract}

Key Words: Cytomegalovirus, Enteritis, Hemodialysis, Ileitis

\section{INTRODUCTION}

Cytomegalovirus (CMV) is predominantly an opportunistic infection in the immunocompromised patient. Isolated CMV is seldom reported. We report a case of CMV enteritis in a immunocompromised hemodialysis patient.

\section{CASe PResentation}

We present a case of a 87 -year-old man, who presented to our dialysis unit with diffuse abdominal pain and nausea. No other complaints such as vomiting, altered stool pattern or fever were present. The patient had a history of arterial

\footnotetext{
*Correspondence: Liesbeth De Waele; Email: dewaeleliesbeth1987@ gmail.com; Address: Antwerp University Hospital, Antwerp, Wilrijkstraat 10, 2650 Edegem, Belgium.
}

Published by Sciedu Press 
hypertension, appendectomy, hypertrofic cardiomyopathy, chronic atrial fibrillation, type 2 diabetes mellitus and endstage chronic renal disease caused by ischemic nephropathy with dialysis dependency since January 2014.

Physical examination revealed a diffuse abdominal pressure pain.

Laboratory findings showed hyperkalemia of $7.0 \mathrm{mmol} / \mathrm{L}$ (range 3.5-5.1 mmol/L) (without hemolysis), leukocytosis of $16 \times 10^{9} / \mathrm{L}$ with neutrophilia, and elevation of CRP (346 mg/L; range 0.1-5 mg/L). Cardiac enzymes were normal. Electrocardiography revealed peaked $\mathrm{T}$ waves.

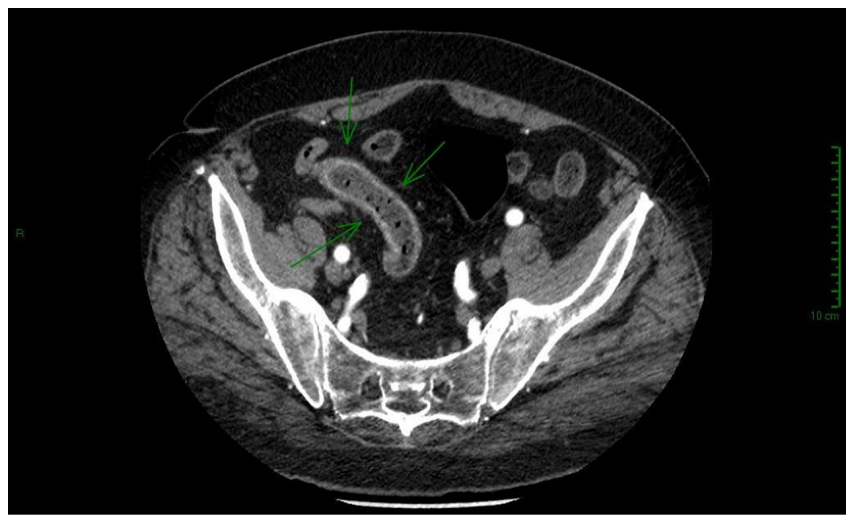

Figure 1. CT scan showed a thickening of the wall of the preterminal ileum

Further assessment with a computed tomography scan (CT) of the abdomen showed a thickening of the wall of the preterminal ileum (see Figure 1), suggestive of focal enteritis. There were no signs of bowel obstruction. Further exploration with ileocolonoscopy showed a partial circular ulcerated mucosa of the preterminal ileum, biopsies were taken and showed ulcerations with granulation tissue, etiology was unknown.

Because of suspicion of ischemia, a CT angiography of the abdomen was performed and showed a $50 \%$ stenosis of the truncus coeliacus and $70 \%$ stenosis of arteria mesenterica superior (see Figure 2). No abnormalities of the arteria mesenterica inferior were seen. A platelet aggregation inhibitor (acetylsalicylic acid $80 \mathrm{mg}$ once daily) was started on advice of the vascular surgeon.

One week later the patient was hospitalized with complaints of melena. Laboratory results showed anemia of $7.2 \mathrm{~g} / \mathrm{dl}$ (range: $13-16 \mathrm{~g} / \mathrm{dl}$ ). Further assessment with gastroscopy was normal. A colonoscopy was again performed and showed no abnormalities; however the terminal ileum could not be visualized. An urgent laparotomy was performed because of hemodynamic instability and showed an ulcus of $7 \mathrm{~cm}$ with a thickened, edematous terminal ileum, without signs of ischemia. An enterectomy of the inflammated part of the ileum was done. Histopathology showed an ulceration of the terminal ileum with presence of CMV inclusions in the vascular endothelium of the capillaires of the ileal segment. Serologic examination showed presentation of CMV IgM antibodies were nonreactive and low ranged. IgG antibodies which were positive. PCR CMV showed 300 copies/ml (whole blood).

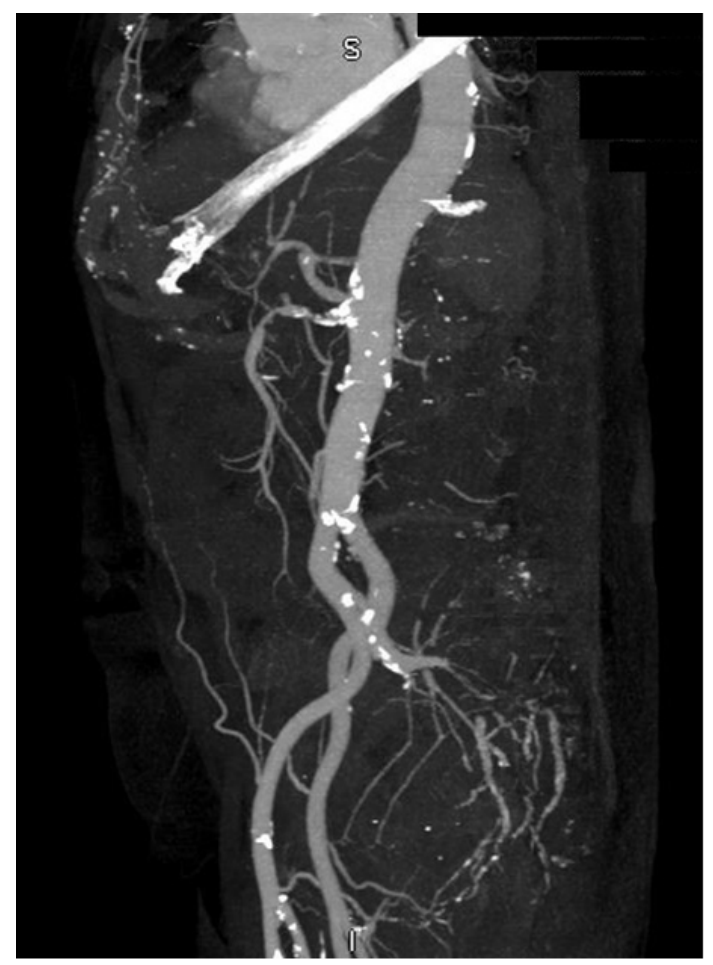

Figure 2. CT angiography showed a 70\% stenosis of arteria mesenterica superior

The diagnosis of CMV ileitis was established on histopathological basis and treatment with intravenous ganciclovir (1.25 mg/kg $3 \times /$ weekly following dialysis) was started with good clinical and biochemical response.

But unfortunately the patient developed acute abdominal pain with hemodynamic instability leading to death. An autopsy was performed and showed ischemia of the ileum and colon with detachment of the suture of the terminal ileum, probably secondary to the ischemia.

\section{Discussion}

CMV infection is a common viral infection in humans, but the manifestation is diverse and mostly dependent on the host. CMV infection in the immunocompetent host is generally asymptomatic or may present as a mononucleosis syndrome. 
Infection in immunocompromised patients cause substantial morbidity and mortality. ${ }^{[1,2]}$

In this case the patient can be considered as immunocompromised as he has end-stage renal failure and he is dialysis dependent and has diabetes.

CMV enteritis can infect the entire gastrointestinal tract from the oesophagus to the rectum, with the most frequent site being the colon. ${ }^{[3]} \mathrm{CMV}$ infections of the small bowel are very seldom. ${ }^{[4]}$ CMV enteritis presents mostly by diarrhea and abdominal pain and can be presented by his complications as perforation secondary to ileal ulceration. ${ }^{[5,6]}$ Ileal ulcerations are in case reports described as two perforated small-bowel ulcers ${ }^{[6]}$ or as segmental ischemic changes and ulceration with a marked transition from normal mucosa. ${ }^{[7]}$ In those reports the size of the ulcerations was not mentioned.

The pathogenesis of CMV-induced ulceration is related to ischemic mucosal injury secondary to infection of the vascular endothelial cells. ${ }^{[8]}$

Diagnosis is difficult to make and mostly delayed, mainly because CMV enteritis has the ability to mimic many diseases, such as ischemia, inflammatory bowel diseases, colitis caused by $C$. difficile..$^{[9,10]}$

The diagnosis can be confirmed by performing histology on biopsies of the terminal ileum. ${ }^{[1]}$

Serological tests, such as CMV IgM, IgG antibodies and CMV viral load testing were done in this case and showed a low $\operatorname{IgG}$ and slightly elevated IgM. However the role of these tests in detecting CMV infection before the onset of CMV gastro-intestinal disease is not conclusive. ${ }^{[12]}$ Further- more, as in our case, some cases of compartmentalized or localized CMV diseases have very low or transient periods of viremia. ${ }^{[13,14]}$

On the other hand, follow-up viral load testing is useful when the decision is made to initiate treatment, testing of the viral load should be performed the day the therapy starts, followed by viral load testing with 5 - to 7-day intervals, because the half-life of CMV DNA in the plasma ranges from 3 to 8 days. ${ }^{[15]}$

Antiviral drugs such as ganciclovir and foscarnet are the first-line treatment for clinically significant CMV infection. Treatment with antiviral therapy is advised in immunocompromised patients of advancing age ( $>55$ years), male sex and immunomodulating conditions as pregnancy, chronic renal failure, diabetes and untreated non-hematological malignancy, as seen in a meta-analysis performed by Galiatsatos et al. In patients younger than 55 years of age with no other comorbidities treatment with antiviral drugs is not advised as a spontaneous resolution is to be expected. ${ }^{[16]}$

\section{Conclusion}

$\mathrm{CMV}$ enteritis is a rare manifestation of CMV disease that could possible lead to ulceration complicated by perforation and bleeding.

In the differential diagnosis CMV disease should be considered in any ulceration in the gastro-intestinal tract in the immunocompromised patient.

\section{CONFlicts of InTEREST Disclosure}

The authors have declared no conflicts of interest.

\section{REFERENCES}

[1] Cohen JI, Corey GR. Cytomegalovirus infection in the normal host. Medicine (Baltimore). 1985; 64: 100. https://doi.org/10.109 7/00005792-198503000-00003

[2] Horwitz CA, Henle W, Henle G, et al. Clinical and laboratory evaluation of cytomegalovirus-induced mononucleosis in previously healthy individuals. Report of 82 cases. Medicine (Baltimore). 1986; 65: 124. https://doi.org/10.1097/00005792-198603000-00005

[3] Ko JH, Peck KR, Lee WJ, et al. Clinical presentation and risk factors for cytomegalovirus colitis in immunocompetent adult patients. Clin. Inf. Dis. 2015; 60 (6): 20-6. PMid:25452594 https : //doi.org/10.1093/cid/ciu969

[4] Taylor GH. Cytomegalovirus. Am Fam Physician. 2003; 67: 519-24. PMid:12588074

[5] Karigane D, Takaya S, Seki Y, et al. Cytomegalovirus enteritis in immunocompetent subjects: A case report and review of literature. Journal of Infection and Chemotherapy. 2004; 20: 325-9. PMid:24751234 https://doi.org/10.1016/j.jiac.2013.12.004
[6] Michalopoulos N, Triantafillopoulou K, Beretouli E, et al. Small bowel perforation due to CMV enteritis infection in an HIV-positive patient. BMC Res Notes. 2013; 6: 45. PMid:23379792 https : //doi.org/10.1186/1756-0500-6-45

[7] Zainab N, Rasika H, Muslim M, et al. Cytomegalovirus enteritis with ischemia in an immunocompetent patient: A rare case report. Int J Surg Case Rep. 2015; 15: 146-8. PMid:26363106 https://doi.org/10.1016/j.ijscr.2015.08.040

[8] Keates J, Lagahee S, Crilley P, et al. CMV enteritis causing segmental ischemia and massive intestinal hemorrhage. Gastrointest Endosc. 2001; 53: 355-9. https://doi.org/10.1016/S0016-5107(01 ) 70417-8

[9] Siegal DS, Hamid N, Cunha BA. Cytomegalovirus colitis mimicking ischemic colitis in an immunocompetent host. Heart Lung. 2005; 34: 291-4. PMid:16027652 https://doi.org/10.1016/j.hrtl ng. 2004.08 .009

[10] Caroline DF, Hilpert PL, Russin VL. CMV colitis mimicking Crohn's disease in a patient with acquired immune deficiency syndrome 
(AIDS), Can Assoc Radiol J. 1987; 38: 227-8. PMid:2821006

[11] Cha JM, Lee JI, Choe JW, et al. Cytomegalovirus enteritis causing ileal perforation in an elderly immunocompetent individual. Yonsei Med. J. 2010; 51(2): 279-83. PMid:20191024 https ://doi .org/ 10.3349/ymj.2010.51.2.279

[12] Mori T, Mori S, Kanda Y, et al. Clinicial significance of cytomegalovirus (CMV) antigenemia in the prediction and diagnosis of gastrointestinal disease after allogeneic hematopoietic stem cell transplantation. Bone marrow transplant. 2004; 33: 431-4. PMid:14676775 https://doi.org/10.1038/sj.bmt. 1704369

[13] Razonable R, Humar A. Cytomegalovirus in solid organ transplant recipients. Am. J. Transplant. 2013; 13: 93-106. PMid:23465003 https://doi.org/10.1111/ajt.12103
[14] Beam E, Razonable RR. Cytomegalovirus in solid organ transplantation: epidemiology, prevention, and treatment. Curr. Infect. Dis. Rep. 2012; 14: 633-41. PMid:22992839 https ://doi.org/10.1007/ s11908-012-0292-2

[15] Humar A, Kumar D, Boivin G, et al. Cytomegalovirus (CMV) virus load kinetics to predict recurrent disease in solid-organ transplant patients with CMV disease. J Infect Dis. 2002; 186(6): 829 PMid:12198618 https ://doi.org/10.1086/342601

[16] Galiatsatos P, Shrier I, Lamoureux E, et al. Meta-analysis of outcome of cytomegalovirus colitis in immunocompetent hosts. Dig Dis Sci. 2005; 50(4): 609. PMid:15844689 https://doi.org/10.1007/ s10620-005-2544-6 